\title{
Strategic Governance: how to assess board effectiveness in guiding strategy execution
}

\section{Sascha L. Schmidt* and Matthias Brauer**}

Subsequent to a host of corporate corruption scandals, boards of directors are facing amplified pressure from investors, creditors and shareholders in a bid to ensure effective corporate governance of their investments. In previous research and public debate, the effectiveness of corporate governance structures has come under close scrutiny. However, boards' effectiveness in fulfilling their strategic role by guiding strategy execution mostly has been left unaddressed. Due to the high degree of secrecy and sensitivity of strategy issues, boards' effectiveness in guiding strategy execution is much more difficult to assess externally compared to structural governance issues. Against the backdrop of these difficulties and based upon insights from strategy process research, we suggest taking "strategy consistency" between a firm's resource allocation and its announced strategy as a proxy for boards' effectiveness in guiding strategy execution. In doing so, the paper contributes to extant research by going beyond structural governance issues and paying direct attention to strategic governance issues. Specifically, the paper develops a new approach and set of standard measures to assess boards' effectiveness in strategy execution.

Keywords: Corporate governance, board effectiveness, corporate strategy, strategy consistency, rating agencies

\section{Introduction}

fter several years of numerous corporate
governance scandals, endless regulatory
inquiries, new codes of conduct (e.g. Cadbury
Report in the UK, Preda Code in Italy, Vienot
Report in France, German Corporate Gover-
nance Code) and increased shareholder acti-
vism (e.g. driven by CalPers and TIAA-CREF),
the ominous cloud over corporate America
seems to be lifting gradually. "We have made
more reforms in the past two years than in the
past twenty years. Companies need time to
absorb these changes", says Jeff Henley,
chairman and chief financial officer of Oracle
(Michaels and Roberts, 2004, p. 3). Consequent
to the increase in legal regulation of gover-
nance issues, corporations have been forced
primarily to institutionalise suitable gover- nance structures. For instance, the SarbanesOxley Act regularises how internal controls must be revamped, tested and audited. Furthermore, boards have been reconstituted to increase the number of non-executive directors and audit committees are encouraged to drill external auditors.

What still remains evident is a general loss of investors' trust in corporations' governance capabilities. Integrity and competence of boards of directors have been questioned publicly and scrutinised by governmental corporate governance commissions (e.g. Berlin Initiative, Cromme commission) and institutional shareholder service agencies (e.g. Institutional Shareholder Services). Within the climate of new corporate governance rules, the question arises as to whether or not boards of directors, motivated by the fear of protecting
*Address for correspondence: European Business School/ Institute of Management, University of St Gallen, Dufourstrasse 40a, CH-9000 St Gallen, Switzerland. Tel: +4179786 7774; Fax: +41 71224 2355; Email:

sascha.schmidt@unisg.ch

**The two authors have contributed equally to the paper. 
reputation and limiting liability, are now focusing too heavily on checklists and box ticking instead of strategic issues (Van der Walt and Ingley, 2001; Sonnenfeld, 2004). In this respect, Roderick Hills, former chairman of the SEC, recently told the Financial Times that new rules run the danger of paralysing corporate leadership: "You can find legal firms that send out checklists [for compliance]. That can turn boards into robots" (Michaels and Roberts, 2004, p. 2).

The checklist approach leading to (over) standardisation of corporate governance structures, however, has another major caveat: a credible link between "structural governance standards" and firm performance has yet to be established (for an extensive discussion see Dalton et al., 1998). This has cast further doubts upon the research focus on structural aspects, especially, since differentiating effective from ineffective practices through a screening of structural aspects of corporate governance becomes increasingly difficult when all firms maintain the same structural governance standards. It continues to remain unclear how these structures in fact impact boards' actions in the specific case.

Instead, the dynamics of actual board behaviour in respect to strategic decision making, the teamwork of board members and their interaction with management have been suggested to be more reliable indicators of effective governance practices (Finkelstein and Hambrick, 1996; Daily et al., 2003; Finkelstein and Mooney, 2003; Sonnenfeld, 2004; Huse, 2005). In this context, boards' strategic role which comprises the oversight of strategy formulation and execution has become of major interest (Zahra and Pearce, 1989; Zahra, 1990; O'Neal and Thomas, 1995; Westphal and Zajac, 1995; Finkelstein and Hambrick, 1996; McNulty and Pettigrew, 1999; Stiles, 2001; Felton and Watson, 2002; Useem, 2003). Most importantly, boards are exhorted to participate more actively not only in strategy formulation (e.g. reviewing, ratifying and evaluating the proposed strategy) but also in strategy execution to contribute to corporate value creation (Goold and Campbell, 1990; Zahra, 1990). As a result it seems important to assess boards' effectiveness in guiding strategy execution.

But despite the acknowledged importance of monitoring whether boards fulfil their strategic tasks, board evaluations fail to be a widespread practice (see Blake, 1999; Davies, 1999; Letendre, 2004; Sonnenfeld, 2004). For instance, the Dey Report, a survey of 635 executives, indicates that less than 20 per cent of Canadian companies have any formal process in place to assess the effectiveness of their boards (see Kazanjian, 2000). Most of all, there seem to be a lack of adequate methods and measures for assessing the effectiveness of boards in guiding strategy execution.

This paper takes a first tentative step to fill this gap. Based on current practices for assessing boards' effectiveness (e.g. van der Walt and Ingley, 2001; Siciliano, 2002; Sonnenfeld, 2004) and insights from strategy process research (e.g. Mintzberg and Waters, 1982; Van de Ven, 1992; Chakravarthy and White, 2001), we suggest a new approach on how to assess boards' effectiveness in guiding strategy execution. Specifically, we propose strategy consistency, measuring the consistency between a firm's resource allocation and its announced strategy, as well as a set of related strategy consistency measures as proxies for a board's effectiveness in guiding strategy execution. In doing so, the study is among the first to develop a theoretically grounded and practically doable approach for assessing boards' effectiveness in fulfilling their strategic tasks. The corresponding measures introduced in the paper aim to serve as a basis for future comparative research on the effectiveness of boards in strategy execution.

We have structured this paper as follows. First, we critically review standard practices on assessing board's effectiveness. Then, against the backdrop of the shortcomings of current practices in assessing board effectiveness and based on insights from strategy process research, we propose the measurement of strategy consistency as an alternative approach to how boards' effectiveness in strategy execution may be assessed. We conclude with a discussion of the benefits and implications of such an approach.

\section{Self assessments of boards' effectiveness and their methodological flaws}

Shareholders have the right to expect that boards of directors scrutinise their own performance in carrying out their corporate governance responsibilities on a regular basis (Lazonick and O'Sullivan, 2000). In companies in which self-assessments are institutionalised, board members meet - usually on an annual basis - to question their own performance and to identify improvement potential regarding, for example, the quality of discussions at board meetings, support provided to the executive management, interaction within the board and with the management etc. Of course, answering the questions of who contributed what and who needs to increase the involvement on an individual level is part of boards' self-assessment. 
From a scientific perspective, the reliance on self-assessments as a primary means for board evaluation is questionable (Carcio, 2004; Sonnenfeld, 2004). We know from prior experience that self-evaluation is problematic due to the fact that boards of directors tend to be "more lenient, less variable, more biased, and show less agreement with the judgement of others" (Carcio, 2004, p. 100). One of the reasons might be that directors are normally highly exposed individuals with a strong track record but unaccustomed to be once again exposed to assessments and personal development questions. This problem probably increases with greater seniority of directors.

A second major weakness of self-assessments of board effectiveness is that the evaluation runs the danger of being politically shaped (Grady, 1999). Fellow board members might be hesitant to challenge each other's performance in peer evaluations (Byrd and Hickman, 1992). In addition, under-performing directors may feel obliged to form coalitions within the board to avoid negative evaluations. These problems might lead to deterioration rather than an improvement of board effectiveness. The involvement of external consultants who facilitate the self-assessment might ensure some professionalism in the evaluation process but does not solve latter problems satisfactorily. Given these numerous shortcomings of self-assessments they should be used only as supplementary to external evaluations.

In order to avoid the problems inherent with self-assessment of boards of directors (e.g. biases; erosion of collegiality etc.), third party or audit committee reviews are a popular practice for board assessments. According to a study by Tricker (1999), one-third of the largest firms in the US have reported to have formal board evaluations conducted by either the audit committee or outside experts. Also, the Korn/Ferry annual international survey reports that almost 60 per cent of the respondents have a formal committee that oversees corporate governance processes and board operations (see Ferry, 1999; Marshall, 2001). Financial analysts, institutional investors and liability underwriters often rely on external reviews from rating agencies, index providers or specialised consultants that are systematically tracking the corporate governance effectiveness of corporations from an independent outside perspective.

External reviewers, on the one hand, clearly have the advantage of providing an objective picture from an outside perspective based on information that has not been filtered inside the corporation. On the other hand, the limiting factor is, of course, that they usually do not have access to strategy workshops and board meetings and cannot really observe the vigilance of boards in executing their strategy tasks. Without opportunities for direct observation, board dynamics cannot be captured in their entirety - encompassing individual thought processes and interactive politically shaped decision-making.

\section{Third party assessments of boards' effectiveness and their methodological flaws}

Unfortunately, the attention of external reviewers (rating agencies, governance consultants, audit committees etc.) directed towards board of directors' behaviour - specifically in strategy formulation and execution - has remained sparse; they have collectively failed to provide appropriate metrics (Sonnenfeld, 2004). For instance, Standard \& Poor's which launched a corporate governance scoring service in 2000 - claims that "the board should play a meaningful role in directing the articulation and implementation of the company's strategy" (Standard \& Poor's Governance Services, 2003, p. 13). But the applied checklist type of assessment is limited to output measures of board of directors' activities such as attendance rates, or meeting frequency. It remains unclear how S\&P tracks whether boards just participate or play a "meaningful role" in strategy formulation and execution. Output measures should thus be complemented by process measures to capture the dynamics of board behaviour. A meaningful role for boards of directors in strategy processes might be ensuring consistency between the announced and the actually executed strategy over time (Richter and Schmidt, 2005). By continuously monitoring whether managers comply with agreed upon strategies or diverge from them, the board guarantees its share- and stakeholders that the corporation really "walks like it talks" (McGregor, 1967; Weick, 1995) or "aligns words and deeds" (Simons, 1999, 2002a, 2002b).

As a rule, rating agencies like Governance Metrics International or Institutional Shareholder Service evaluate the effectiveness of corporate governance by ratings, surveys and indices. They take firms' compliance with corporate governance codes of conduct as a primary measure for the effectiveness of boards of directors. Thus, rating criteria are often based on a synthesis of existing international codes and governance best practices edited by private or regulatory expert commissions (e.g. Cadbury Report in UK, Preda Code in Italy, Vienot Report in France, German Corporate 
Governance Code) or supranational organisations (e.g. Standard \& Poor's Governance Services). Corporate governance codes generally stipulate guidelines for board composition, ownership structures, number of executive vs non-executive directors, committee structures and executive compensation schemes, for example. By complying with these codes corporations expect to increase their credibility and legitimacy in the view of investors, capital suppliers and so on.

Accompanying rating agencies' efforts, various financial information providers are currently trying to translate corporate information into a corporate governance index. They aim at providing benchmark data on how well companies are governed. For instance, FTSE announced the launch of such a corporate governance index in cooperation with Institutional Investor Services (ISS), a provider of proxy voting and corporate governance services. Together they identified a set of corporate governance principles, which will be applied to rate the 7,000 companies within the FTSE Global Equity Index Series. Design and methodology of the index draw on ISS's experience in developing the Corporate Governance Quotient ${ }^{\circledR}$. Similar to corporate governance rating systems, indices take structural aspects such as board composition and independence, executive and director compensation, company ownership and audit independence as proxies for corporate governance practice (e.g. FTSE/ISS Global Corporate Governance Index).

A principal weakness of external corporate governance reviews is that "little scientific rigor has been applied" and most of the current corporate governance metrics are "anchored more in clichés and myths rather than careful research" (Sonnenfeld, 2004, p. 108). Existing rating methods are not reliable and accurate enough to justify the attention they gain. Even established providers of corporate governance assessments concede that the biggest difficulty is in establishing an agreed corporate governance rating system or that the process of governance scoring is as much of an art as a science (see Standard \& Poor's Governance Services, 2003). Accordingly, Mirza Baig, corporate governance analyst at the Association of British Insurers, says: "Corporate governance is very difficult to measure - there are so many variable factors and so many subjective areas" (Gascoigne, 2004 , p. 10). In fact, there is a gap within the scientific perception and appraisement of corporate governance that cannot be compensated by structural corporate governance aspects. They are not really helpful for differentiating effective from ineffective corporate governance practices. Admittedly, it has remained unclear if in fact good corporate governance improves stock price performance. As of today, no scientific study has been able to confirm that structural dimensions of corporate governance correlate with financial performance. In several cases, empirical findings supporting the governance structure-performance link are misleadingly cited, yet while taking a closer look, they are in fact not supportive (for an overview see Dalton et al., 1998). It is probably fair to say that none of these studies has yet been able to fully establish a causal relationship between board effectiveness and organisational performance. Naturally, this is partly due to the complexity of the relationship (see Cadbury, 1997; Herman and Renz, 2000).

The readily measurable and rather simplistic structural elements on which current corporate governance assessments are predominantly built upon have been found to have limited impact on the effectiveness of boards of directors. Thus effective governance cannot be distinguished from ineffective governance through variations in governance structures. In addition, it accrues from a strategic management point of view, that even if we assume a positive governance structureperformance relationship, a competitive advantage through superior governance structures can only be of temporary nature. Once every corporation has complied with structural requirements set by established codes of conduct, the initial source of differentiation is going to disappear. Accordingly, the emphasis should be shifted towards alternative differentiation factors that lie in how boards are run, how they interplay with senior management, and how they impact strategy formulation and execution.

In summary, two major roadblocks for sufficient external board evaluations exist. First, external reviews focus on structural governance aspects that have been found to bear little impact on firm performance. Second, they lack sufficient methodological rigor. Consequently, new approaches and metrics need to be designed to reliably assess the effectiveness of boards of directors in strategy execution.

\section{How to conceive and analyse board's role in strategy execution outside-in}

Since it is in the interest of both boards of directors and respective shareholder and stakeholder groups to fairly evaluate board effectiveness in guiding strategy execution, a third-party approach has some appeal because 
it promises to be more objective than selfassessments - always assuming that the outside reviewers preserve anonymity and integrity of the assessment process. But we know from empirical work in social sciences that examining actual board behaviour is a very tough exercise to undertake - especially so, if strategic issues are concerned (Sonnenfeld, 2004; Huse, 2005). One of the biggest problems is that, unlike other forms of financial analysis for which quantitative measures can provide some definitive benchmarks to guide more qualitative aspects of analysis, the assessment of board behaviour remains largely a qualitative exercise (Sonnenfeld, 2004).

Board members operate in highly secretive and sensitive areas, which are usually not conducive to direct observation (Huse, 2005). They have incentives to keep certain information confidential and present a well-prepared storyline to capital markets. Even in face-toface meetings it is challenging to gain insights into the "black box" of how boards contribute to strategic decision-making (Finkelstein and Mooney, 2003).

In order to surmount these difficulties of gaining insights into strategic governance issues, we propose to look at how the field of strategy process has managed to overcome very similar challenges (e.g. Mintzberg and Waters, 1982; Pettigrew, 1992; Van de Ven, 1992; Chakravarthy and White, 2001). Strategy process research centres on the investigation of strategy formulation, execution and strategic change (e.g. Pettigrew, 1987; Van de Ven, 1992). Similar to governance researchers, strategy process scholars experienced "real-time studies of strategy process as being difficult. It is unlikely that a firm engaged in a new strategy would allow a team of researchers to observe its evolution from multiple vantage points" (Chakravarthy and White, 2001, p. 201). Based on the experience from multiple case studies at leading firms such as Intel (e.g. Burgelman, 1983, 1994, 1996), strategy process researchers have begun to understand that the primary focus cannot be the company's vision and mission statements alone, but rather whether or not the firms really "walk their talk" (McGregor, 1967; Weick, 1995) or "align words and deeds" (Simons, 1999, 2002a, 2002b).

Consequently, in order to conceive and analyse strategic behaviour, strategy process researchers have taken resource allocation decisions as access to the ongoing activities of a firm's management and board (Bower, 1970; Burgelman, 1983; Mintzberg and Waters, 1985; Van de Ven et al., 1989). In a well-known article Mintzberg and Waters (1985) have argued that the intended or unintended strategy of the firm materialises through resource allocation. In the form of clinical case studies, researchers such as Bower (1970), Noda and Bower (1996) as well as Burgelman (1983, 1994, 1996) gathered information about resource allocation decisions from public (e.g. news releases) and archival sources (e.g. company presentations, conference minutes) and thus approximated the strategic behaviour on multiple management levels.

Along the same lines, we think that using resource allocation decisions as indicators for strategic behaviour of boards of directors seems justified since resource allocation is at the core of board of directors' mandates (McNulty and Pettigrew, 1999). In fact, some researcher's (e.g. Prigge, 1999) have pointed out that the monitoring of resource allocation decisions constitutes the essence of corporate governance. Boards of directors agree with the executive management on a firm's strategy (Westphal and Fredrickson, 2001; Hillman and Danziel, 2003), which provides direction and serves as a benchmark for allocating resources among competing strategic initiatives and projects. Boards of directors as a whole and especially non-executive board members - usually do not make any business-level decisions themselves (Harrison, 1987). Instead they establish an internal context that shapes the preparation, championing and approval of resource allocation decisions made by the executive management or by managers in the business units (see, for example, Collis and Montgomery, 1997; Papadakis and Barwiese, 1997; Westphal and Fredrickson, 2001).

On the other side, it can be seen as a central part of a board of directors' role to ensure that the firm's executed strategy, that is, its actual resource allocation decisions, are consistent with the announced strategy. Accordingly, consistency in resource allocation as a rule can be taken as a measure for directors' effectiveness in guiding the announced strategy's execution.

In order to track whether a firm's resource allocation decisions are consistent with the announced strategy, external reviewers such as rating agencies, governance consultants or audit committees could systematically collect, categorise and evaluate all available data on firms' resource transactions. In general, data on resource allocation is easily accessible as publicly listed firms are required to publicise important resource transactions, such as acquisitions, layoffs, divestments, investments, cooperations, joint ventures etc. Corporations themselves have an interest in providing reliable information given that it shapes the opinion of shareholders and other interest groups. The reliability of this infor- 
mation can be checked by comparing multiple data sources (so called data triangulation). In some instances the data which are gathered have already been triangulated, since professional news agencies such as Bloomberg or Reuters only report news if these have been validated by multiple sources.

Apparently well-formulated qualitative retrospectives or interpretations by themselves do not meet the requirements of an effectiveness evaluation. In fact, precise and data-based quantitative information about actual strategy execution activities should also be gathered to allow for an assessment of boards' effectiveness in guiding strategy execution. As an initial step, resource allocation decisions taken from any publicly available source (e.g. annual reports, proxy statements, filings with government regulatory agencies, records of shareholder meetings, releases from news agencies) providing information on firms' executed and intended resource allocations need to be gathered in a standardised format. Database programs can assist in transforming heterogeneous data into a joint format. This seems essential given that calibre, context and degree of this information may vary amongst the different data sources. A joint and standardised format may be achieved by coding the resource allocation decisions along pre-specified "tracks" (for a similar approach see Van de Ven et al., 1999). Potential database tracks could refer to the type of resource allocation actions (e.g. investment, divestment and cooperation), the affected resource type (e.g. physical, human, technological, financial), the decision-making level (corporate, divisional, operational), the acting and affected business unit, region, functional area or the volume of a transaction.

As a second step, we propose that the consistency between each single resource allocation incident and the announced strategy is assessed. Zurich-based Sustainable Asset Management (SAM), for instance, does a similar kind of consistency test. Within the frame of its Corporate Sustainability Monitoring the consistency of a company's behaviour and management of crisis situations is reviewed in line with its stated principles and policies. In doing so, SAM rather deals with selected points of commercial practices (e.g. human rights abuses, layoffs or workforce conflicts) in crisis situations but does not really investigate corporate behaviour over time - as we are accustomed to from longitudinal case studies in strategy process research (Bower, 1970; Burgelman, 1983; Pettigrew, 1992; Van de Ven et al., 1989).

Instead, we propose taking the publicly announced strategy of a company as the benchmark to assess the consistency of resource allocation decisions (Richter and Schmidt, 2005; Schmidt, 2005). According to established qualitative research methods in social sciences (e.g. Strauss, 1987; Miles and Huberman, 1994) each resource allocation incident is coded as to whether it is (a) in line with the announced strategy or (b) contrary to it. If the incident's relationship with the firm's announced corporate strategy is unclear, it is coded as neutral.

In order to ensure quality and objectivity of the consistency assessment multiple coders should do the assessment independently. Only if a satisfying interrater reliability can be achieved should coded resource allocation incidents be included in the database. Developing a handbook with instructions for the coding procedure helps to ensure that individual assessments are based on the same rationale. A single resource allocation incident might not be very meaningful. However, hundreds of resource allocation incidents give clear indications as to whether resource allocations are consistent with the announced strategy over time or not.

Of course, a firm can announce a particular strategy and then allocate its resources differently, which could be intentional or not. In the latter case, resource allocation could result from social or political processes that deviate from the given strategy. Ensuring consistency between the announced strategy and individual resource allocations should be a prime concern for boards of directors (see Burgelman and Grove, 1996). After all, if the resource allocation decisions in an organisation do not correspond with the announced strategy, this missing link should raise serious concerns about the relevance of having a strategy in the first place. In any case, the board of directors should be aware of both intended and unintended gaps between the announced strategy and actual resource allocation in order to take or at least initiate corrective action (e.g. realign strategy or resource allocation).

\section{Benefits}

The proposed strategy consistency analysis can deliver interesting insights into strategy execution and warning alerts. Board of directors' vigilance to strategic issues and its response to inconsistencies in strategy execution seem suitable yardsticks for boards' effectiveness in guiding strategy execution.

Frankly, bare strategy consistency should not be taken as inexorable proof for effective strategic board behaviour. Strategy consistency thus should not be used as the single 
indicator of board effectiveness in guiding strategy execution. As mentioned, numerous strategy-related output (e.g. ROE, ROIC) and process (e.g. speed of intervention, timely communication to shareholders) measures should be combined in order to prevent measurement inadequacies which are apparent in structural governance measures today. But still, measuring and analysing strategy consistency provides a number of benefits.

First of all, the systematic and standardised assessment of resource allocation decisions enables third parties such as rating agencies, analysts, consultants and scholars an "objective" comparison between peer companies. For instance, two pharmaceutical companies which announced a similar strategy (e.g. focusing on blockbuster drugs) could be compared according to their degree of strategy consistency at one point in time or multiple points over time (e.g. on a weekly, monthly, quarterly or annual basis). Firms with a higher volatility in their strategy consistency over time might be less reliant in the view of investors or at least are required to explain divergent resource allocations to the public. Along these lines, a pharmaceutical company would need to communicate why it invests in niche therapeutic areas while having announced a strategy focusing on blockbuster drugs.

Second, strategy consistency measures also allow a comparison of the effectiveness of board interventions (e.g. replacement of the CEO, launch of a new strategy, adjustment of top-management compensation structures). For instance, the effectiveness of boards can vary in terms of board intervention speed (i.e. how quickly boards of directors react to divergences of resource allocations from the announced strategy), time to reach strategy consistency (i.e. how quickly intended and realised strategy can be realigned, for instance, through changes in the announced strategy or in the resource allocation), or time to next inconsistency (i.e. how strategy consistency lasts after a board intervention). This approach thus allows the analysis of boards' judgement on when (e.g. timing, speed) and how (e.g. behavioural aspect of interventions) to react on strategic divergences - a key success factor for the "strategic" effectiveness of boards of directors. Naturally, it has to be borne in mind that the "quality" of interventions not only hinges on the process and behavioural aspects, but also on structural aspects, such as board expertise and composition.

Knowing the appropriate time to react to strategy inconsistencies is important since desirable levels of strategy consistency are likely to vary across industries depending on how dynamic the environment is. For instance, high velocity environments might require higher levels of strategic flexibility and thus impact firm's suitable level of strategy (in)consistency. In order to catch emerging opportunities, the optimal strategy consistency bandwidth might vary from industry to industry and is dependent on the individual situation of a firm (financial performance, track record) and its competitive position. Potentially, boards thus need to strive for a level of strategy consistency which satisfies share- and stakeholders that look for consistency on the one hand, but also permits executive management to follow business opportunities outside the initially formulated strategy. Obviously, the dynamism of a firm's competitive environment needs to be considered when evaluating board's effectiveness in guiding strategy execution. Of course, circumstances shift and change in business practice so that resource allocation decisions that are inconsistent with the initially announced strategy might be the right answer to unforeseen changes (Mintzberg, 1994). However, this does not call into question the appropriateness of measuring strategy consistency, since we assume that a firm would announce changes to its corporate strategy if it perceives that environmental changes have a long-term impact. The environmental dynamism is thus likely to be reflected in the frequency and extent of additions or adjustments made to a firm's announced strategy.

Moreover, external stakeholders (e.g. capital market representatives) compare firms' resource allocation decisions against their announced strategy. For example, Zurich Financial Services was downgraded by S\&P and Moody's based on the argument that the firm lacked strategy consistency (Reuters News, 2002). Thus, irrespective of the rationale behind inconsistent behaviour, it seems important that strategy inconsistencies are detected and discussed internally as well as explained to a firm's share- and stakeholders. A continuous involvement of boards in strategy execution triggers a critical strategic debate with the executive management which is likely to prevent strategic inertia and helps to avoid unexplained strategy inconsistency.

Overall, the prescriptions made in this paper on how to assess boards' effectiveness in guiding strategy execution seem to be most insightful for non-executive directors as well as third parties. Non-executive directors function at the interface of the firm and its environments and thus seem particularly suited to track the development of the firm's behaviour from the outside. Also, analysts, rating agencies, shareholder trusts, consultants and scholars need to rely on publicly available 
information to judge firm behaviour. Obviously, taking public information as a primary source has its limitations, given that the data are biased to a certain extent in terms of the amount and type of information reported by the firms and the way it is displayed by journalists and news agencies (Silverman, 2000).

However, such a practically attainable and still methodologically sound strategy consistency analysis might create additional benefits for boards of directors that evaluate their corporate governance practices in comparison to other companies' board practices. Firstly, by analysing strategy consistency, early indications of strategic divergence can be made out. By responding to these indications in a timely manner through corrective measures, boards are able intervene before, rather than after damage is done. This is particularly the case in respect of intended resource allocation decisions which are communicated by companies to the financial community but are not yet executed. Plans for a potential acquisition or cooperation agreement often leak to the public or are deliberately communicated prior to their actual execution. Often, companies also announce intended resource allocations in the "letter to shareholders" section of their annual reports (e.g. Siemens, ABB, UBS). Such boards may thus not necessarily be resigned to do simply the "repair work". Doing so, board members could credibly demonstrate their effectiveness in guiding strategy execution.

Moreover, an analysis of strategy consistency allows third parties (analysts, rating agencies, shareholder trusts, consultants, scholars etc.) to conduct insightful interviews with board members. This is particularly important for them since they rely on publicly available information and do not possess insider knowledge. Such an analysis enables them at least to enter a firm as an educated interviewer and to confront board members with identified strategic divergences. He or she can immediately address the motives or omissions for such divergences from the announced strategy. In addition, the discussion of turning points or breakpoints in strategy consistency which could be observed within a certain timeframe is likely to capture the attention of interviewees. Fact-based and well-documented hypotheses gained from the strategy consistency analysis make it difficult for interviewees to refute without providing reasoning for the inconsistencies. Overall, a strategy consistency analysis may thus enable rating agencies, financial service firms and shareholder service agencies to glean deeper insights into one major aspect of a board's strategic behaviour: boards' guidance of strategy execution.

\section{Acknowledgements}

We would like to thank the two anonymous reviewers as well as Günter Müller-Stewens, Ansgar Richter, Jean-Paul Thommen and Martin Welge for their helpful comments. In addition, we thank the members of the EGOS and EURAM corporate governance track for their substantial and helpful feedback on earlier versions of this paper. We would also like to express our thanks to the participants in ICS seminars at the University of St Gallen and the European Business School in 2003 and 2004 for their helpful and supportive comments.

\section{References}

Blake, A. (1999) Dynamic Directors: Aligning Board Structure for Business Success. Basingstoke: Macmillan.

Bower, J. L. (1970) Managing the Resource Allocation Process. Boston: Harvard Business School Press.

Burgelman, R. A. (1983) A Process Model of Internal Corporate Venturing in the Diversified Major Firm, Administrative Science Quarterly, 28, 223244.

Burgelman, R. A. (1994) Fading Memories: A Process Theory of Strategic Business Exit in Dynamic Environments, Administrative Science Quarterly, 39, 24-56.

Burgelman, R. A. (1996) A Process Model of Strategic Business Exit - Implications for an Evolutionary Perspective on Strategy, Strategic Management Journal, 17, 193-214.

Burgelman, R. A. and Grove, A. S. (1996) Strategic Dissonance, California Management Review, 38, 828.

Byrd, J. and Hickman, K. (1992) Do Outside Directors Monitor Managers? Evidence from Tender Offer Bids, Journal of Financial Economics, 32, 195221.

Cadbury, A. (1997) On Coming Up to Code, Directors $\mathcal{E}$ Boards, 21, 96.

Carcio, W. (2004) Board Governance: A Social Systems Perspective, Academy of Management Executive, 18, 100.

Chakravarthy, B. S. and White, R. E. (2001) Strategy process: forming, implementing and changing strategies. In A. Pettigrew, H. Thomas and R. Whittington (eds) Handbook of Strategy and Management, 182-205. London: Sage.

Collis, D. J. and Montgomery, C. A. (1997) Corporate Strategy: Resources and the Scope of the Firm. Irwin: Burr Ridge.

Daily, C. M., Dalton, A. A. and Cannella, A. A. (2003) Corporate Governance: Decades of Dialogue and Data, Academy of Management Review, $28,371-382$.

Dalton, D. R., Daily, C. M., Ellstrand, A. E. and Johnson, J. L. (1998) Meta-Analytic Reviews of Board Composition, Leadership Structure, and Financial Performance, Strategic Management Journal, 24, 269-290.

Davies, A. (1999) A Strategic Approach to Corporate Governance. Aldershot: Gower. 
Felton, R. F. and Watson, M. (2002) Change Across the Board, McKinsey Quarterly, 4, 31-45.

Ferry, R. (1999) Boardrooms Yesterday, Today and Tomorrow, Chief Executive, 142, 44-47.

Finkelstein, S. and Hambrick, D. (1996) Strategic Leadership: Top Executives and their Effects on Organizations. Minneapolis, MN: West.

Finkelstein, S. and Mooney, A. C. (2003) Not the Usual Suspects: How to Use Board Process to Make Boards Better, Academy of Management Executive, 17, 101-113.

Gascoigne, C. (2004) Investors Get a Measure for Corporate Behaviour, Financial Times Series on Corporate Governance, 23 April.

Goold, M. and Campbell, A. (1990) Non-Executive Directors' Role in Strategy, Long Range Planning, 23, 118-119.

Grady, D. (1999) No More Board Games! The McKinsey Quarterly, 3, 17-25.

Harrison, J. (1987) The Strategic Use of Corporate Board Committees, California Management Review, 30, 109-125.

Herman, R. D. and Renz, D. O. (2000) Board Practices of Especially Effective and Less Effective Local Non-Profit Organizations, American Review of Public Administration, 30, 146-160.

Hillmann, A. J. and Danziel, T. (2003) Boards of Directors and Firm Performance: Integrating Agency and Resource Dependence Perspectives, Academy of Management Review, 28, 383-396.

Huse, M. (2005) Accountability and Creating Accountability: A Framework for Exploring Behavioural Perspectives of Corporate Governance, British Journal of Management, 16, 65-79.

Kazanjian, J. (2000) Assessing Boards and Individual Directors, Ivey Business Journal, 64, 45-50.

Lazonick, W. and O'Sullivan, M. (2000) Maximizing Shareholder Value: A New Ideology for Corporate Governance, Economy and Society, 29, 13-35.

Letendre, L. (2004) The Dynamics of the Boardroom, Academy of Management Executive, 18, 101-104.

Marshall, J. (2001) As Boards Shrink, Responsibilities Grow, Financial Executive, 17, 36-39.

McGregor, D. (1967) The Professional Manager. New York: Harper.

McNulty, T. and Pettigrew, A. (1999) Strategists on the Board, Organization Studies, 20, 47-74.

Michaels, A. and Roberts, D. (2004) Compliance Brings Business Benefits, Financial Times Series on Corporate Governance, 23 April.

Miles, M. B. and Huberman, A. M. (1994) An Expanded Sourcebook: Qualitative Data Analysis. Thousand Oaks, CA: Sage.

Mintzberg, H. (1994) The Fall and Rise of Strategic Planning, Harvard Business Review, 72, 107-115.

Mintzberg, H. and Waters, J. A. (1982) Tracking Strategy in an Entrepreneurial Firm, Academy of Management Journal, 25, 465-499.

Mintzberg, H. and Waters, J. A. (1985) Of Strategies, Deliberate and Emergent, Strategic Management Journal, 6, 257-272.

Noda, T. and Bower, J. L. (1996) Strategy Making as Iterated Processes of Resource Allocation, Strategic Management Journal, 17, 159-192.

O'Neal, D. and Thomas, H. (1995) Directors Networks/Director Selection: the Board's Strategic Role, European Management Journal, 13, 79-90.
Papadakis, V. and Barwiese, P. (1997) Strategic Decisions. Dordrecht: Kluwer Academic.

Pettigrew, A. (1987) Researching strategic change. In A. Pettigrew (ed.) The Management of Strategic Change, 337-348. Oxford: Basil Blackwell.

Pettigrew, A. (1992) The Character and Significance of Strategy Process Research, Strategic Management Journal, 13, 5-16.

Prigge, S. (1999) Corporate Governance, Die Betriebswirtschaft, 59, 148-151.

Reuters News (2002) Hueppi resigns as Zurich CEO, 25 February.

Richter, A. and Schmidt, S. L. (2005) How Does Strategy Process Influence Strategy Content? Antecedents of Consistency Between Resource Allocation Decisions and Corporate Strategy, Schmalenbach Business Review, 57, 332-350.

Schmidt, S. L. (2005) Comparative Strategy Process Research: A Methodological Approach. Working Paper 53, Institute of Management, University of St Gallen.

Siciliano, J. (2002) Governance and Strategy Implementation: Expanding the Board's Involvement, Business Horizons, Nov-Dec, 33-38.

Silverman, D. (2000) Analyzing talk and text. In N. K. Denzin and Y. S. Lincoln (eds) Handbook of Qualitative Research, 821-834. Thousand Oaks: Sage.

Simons, T. L. (1999) Behavioral Integrity as a Critical Ingredient for Transformational Leadership, Journal of Organizational Change Management, 12, 89-110.

Simons, T. (2002a) Behavioral Integrity: The Perceived Alignment Between Managers' Words and Deeds as a Research Focus, Organization Science, $13,18-35$.

Simons, T. (2002b) The High Cost of Lost Trust, Harvard Business Review, 80, 18-20.

Sonnenfeld, J. (2004) Good Governance and the Misleading Myth of Bad Metrics, Academy of Management Executive, 18, 108-113.

Standard \& Poor's Governance Services (2003) Corporate Governance Scores and Evaluations. New York: McGraw-Hill.

Stiles, P. (2001) The Impact of the Board on Strategy: An Empirical Examination, Journal of Management Studies, 38, 627-650.

Strauss, A. (1987) Qualitative Data Analysis for Social Scientists. Cambridge: Cambridge University Press.

Tricker, R. I. (1999) Fat Cats and Englishmen, Director, 52, 34.

Useem, M. (2003) Corporate Governance is Directors Making Decisions: Reforming the Outward Foundations for Inside Decision-making, Journal of Management and Governance, 7, 241-253.

Van de Ven, A. H. (1992) Suggestions for Studying Strategy Process - A Research Note, Strategic Management Journal, 13, 169-188.

Van de Ven, A. H., Angel, H. L. and Poole, M. S. (1989) Research on the Management of Innovation. New York: Harper \& Row.

Van de Ven, A. H., Polley, D. E., Garud, R. and Venkataraman, S. (1999) The Innovation Journey. New York: Oxford University Press.

Van der Walt, N. and Ingley, C. (2001) Evaluating Board Effectiveness: The Changing Context of 
Strategic Governance, Journal of Change Management, 1, 313-331.

Weick, K. E. (1995) Sensemaking in Organizations. Thousand Oaks, CA: Sage.

Westphal, J. D. and Fredrickson, J. W. (2001) Who Directs Strategic Change? Director Experience, the Selection of New CEOs, and Change in Corporate Strategy, Strategic Management Journal, 22, 1113-1137.

Westphal, J. D. and Zajac, E. (1995) Who Shall Govern? CEO/Board Power, Demographic Similarity, and New Director Selection, Administrative Science Quarterly, 40, 60-83.

Zahra, S. (1990) Increasing the Board's Involvement in Strategy, Long Range Planning, 23, 109-117.

Zahra, S. and Pearce, J. A. (1989) Boards of Directors and Corporate Financial Performance: A Review and Integrative Model, Journal of Management, 15, 291-334.

Sascha L. Schmidt is Lecturer at the European Business School (EBS) in Oestrich Winkel, Germany, where he is also writing his professor thesis (Habilitation). He initiated the Inter- national Corporate Strategy Project at the University of St Gallen, Switzerland, together with the EBS and the University of Dortmund (http://www.ifb.unisg.ch/ics). Dr Schmidt currently works as Business Builder at aconnect, a premier staffing firm in Zurich. He is a former McKinsey Consultant (1999-2003) and was Visiting Scholar at Harvard Business School (1999). He holds a BA degree from the University of Essen, Germany, and earned his $\mathrm{MA}$ and $\mathrm{PhD}$ in strategic management from the University of Zurich, Switzerland.

Matthias Brauer is co-leader of the International Corporate Strategy Project at the University of St Gallen, Switzerland and lecturer in strategic management and organisational research methods. He earned his BA, $\mathrm{MA}$ and his $\mathrm{PhD}$ in strategic management from the University of St Gallen. His research focus is in the area of corporate governance and strategy. His primary area of expertise is on firm divestitures.

'Companies which have been around for a long time have strong values that result in employees being treated well.' Milton Moskowitz, quoted in the Financial Times, 27 ${ }^{\text {th }}$ October 2005.

'Mandatory disclosure could lead to unfair pressure on institutions from single-issue campaigners who are themselves unaccountable.' Peter Montagnon, FTfm, 31 $1^{\text {st }}$ October 2005. 